\title{
HYSTERESIS IN THE PHYSICAL ADSORPTION OF NITROGEN ON BONE CHAR AND OTHER ADSORBENTS ${ }^{1,2}$
}

\author{
By Leland F. Gleysteen and Victor R. Deitz ${ }^{3}$
}

\section{ABSTRACT}

An investigation has been made of some characteristics of hysteresis in the physical adsorption of nitrogen on bone char, activated carbon, silica gel, and coconut-shell charcoal at $77.4^{\circ} \mathrm{K}$. It was found that hysteresis became less pronounced in the order given, occurring only slightly in coconut-shell charcoal and only from high relative pressures in the pressure range in which the Langmuir equation was not obeyed. It was shown that it was highly probable that a true steady state was attained in the pressure determinations and that the time dependency of adsorption and desorption are compatible with the requirements of diffusion processes. In this paper the theories of hysteresis are reviewed on the basis of capillary condensation, and an alternative interpretation is suggested in terms of the theory of multimolecular adsorption.

\section{CONTENTS}

I. Introduction 1280

II. Experimental procedure

III. Experimental results and discussion

1. Rates of adsorption and desorption

2. Hysteresis determinations _.

IV. Theories of hysteresis in physical adsorption

1. Capillary condensation _..._. 300

2. Multimolecular adsorption

V. Summary

VI. References

\section{INTRODUCTION}

In many cases of physical adsorption of vapors, it has been observed that an adsorption isotherm determined for a system does not, in general, coincide with the desorption isotherm determined on the same system at the same temperature. This phenomenon is known as hysteresis in adsorption.

The possibility of hysteresis in the adsorption and desorption of nitrogen at $77.4^{\circ} \mathrm{K}$, its normal boiling temperature, on bone char and other carbon adsorbents arose naturally in the course of a determination of the surface area per gram of these materials. In a previous publication $[1]^{4}$ an analysis of a large number of adsorption isotherms

1 This investigation has resulted from a joint research project undertaken by the United States and Canadian Cane Sugar Refiners, United States Bone Char Manufacturers, and the National Bureau of Standards.

${ }^{2} \mathrm{~A}$ portion of the material given in this paper was presented before the Division of Sugar Chemistry and

Technology of the American Chemical Society at the Detroit meeting, April 1943.

3 Research Associates at the National Bureau of Standards, representing the United States and Canadian

Cane Sugar Refiners and the United States Bone Char Manufacturers.

- Figures in brackets indicate the literature references at the end of this paper. 
by means of the multimolecular theory of physical adsorption [2] made possible the calculation of the surface areas available for the adsorption of nitrogen. As soon as it was established that hysteresis takes place in adsorption on bone char, it was thought to be desirable to pursue these experiments further and to determine what such investigations could contribute to our knowledge of the structure of carbon adsorbents.

Hysteresis has been studied by many observers in a wide variety of adsorbing systems. In many of these systems adsorbents were capable of swelling, and the adsorbed molecules were often complex. The investigation described in this paper has the advantage of dealing with the simple nitrogen molecule adsorbed on materials that are nonswelling, fairly rigid, and stable toward heating to relatively high temperatures (about $400^{\circ} \mathrm{C}$ ) in vacuum. This evacuating and heating procedure is a necessary prerequisite for the elimination of nonreproducible hysteresis phenomena. In some cases it may even completely eliminate the phenomenon itself.

This paper presents the hysteresis phenomena observed in the adsorption and desorption of nitrogen, at $77^{\circ} \mathrm{K}$, on a new bone char, a spent bone char, an activated carbon, two silica gels, and a coconutshell charcoal. Studies of the approach to the equilibrium in both adsorption and desorption are presented as evidence that these examples of hysteresis are not consequences of failure to reach equilibrium. The explanations of hysteresis and of its possible dependence on the structure of the adsorbent are discussed on the basis of the theory of capillary condensation. An interpretation of hysteresis on the basis of the theory of multimolecular adsorption is suggested.

\section{EXPERIMENTAL PROCEDURE}

The apparatus used in these experiments was described in detail in a previous publication [1]. The method of determining the "dead space" in the sorption bulb and the procedure for obtaining the adsorption isotherms was also described. The procedure for obtaining the desorption points is essentially a reversal of that for obtaining the adsorption points. The nitrogen is removed from the sorption bulb by lowering the pressure in one of two ways: either the mercury level in the gas burette is lowered; or, with the stopcock connecting the gas burette to the sorption bulb closed, nitrogen is pumped out from the gas burette. The new pressure is read and the stopcock to the sorption bulb is again opened. The quantity of nitrogen removed by pumping is readily calculated from the initial and final pressures and the volume of the apparatus.

The adsorption bulbs were thermostated by immersion in a bath of boiling liquid nitrogen. At the time of reading the final pressure for each sorption point, the temperature of the bath was determined by means of a 10-junction copper-constantan thermopile. The liquid. nitrogen was freshly prepared from a commercial tank of waterpumped nitrogen before each experiment. The weighed samples of adsorbent were sealed into the adsorption bulbs, which were then evacuated and heated at $400^{\circ} \mathrm{C}$ for about 18 hours. After the adsorbent had cooled, the dead space was measured with purified helium with the bath of liquid nitrogen in position around the tube. The helium was then removed by pumping, the adsorbent being at 
room temperature. The adsorption and desorption isotherms were then determined.

The adsorbents used in these experiments are the same as previously described [3]. Char 2 is a new bone char containing 6.12 percent of carbon and 0.39 percent of hydrogen. Char 6 is an activated carbon containing 71.90 percent of carbon and 0.47 percent of hydrogen. Char 1 is a coconut-shell charcoal containing 93.88 percent of carbon and 0.63 percent of hydrogen. All materials had been ground and the portions passing through a No. 35 United States Standard Sieve and held on a No. 80 United States Standard Sieve were used.

In order to establish the presence of true equilibria, it is desirable to approach a given state from either side of the equilibrium. In the case of hysteresis this is not possible and it is, therefore, necessary to be sure that a reproducible steady state has been realized for each point. If, for example, in the physical adsorption of nitrogen on bone char, insufficient time had been allowed in both the adsorption and desorption measurements, the true isotherm would lie somewhere between the isotherms determined by such procedures and the indicated hysteresis would be an apparent rather than a true phenomenon. Several kinds of evidence indicate that the observed hysteresis is real and not apparent. This evidence includes data on the rates of adsorption and desorption at various pressures and on the reproducible characteristics of the hysteresis loops.

In observing the progress of adsorption and desorption with the apparatus used in these experiments, it was not possible to make accurate observations at the beginning stages of any point. The initial adsorption was always very rapid, and about 95 percent of the final quantity of gas was adsorbed in the first 2 minutes. With some practice it was found possible to note positions of the mercury levels of the manometer in about 1 minute. The particular volume of the gas burette was held fixed. In reading the manometer the high-pressure side was read at the time assigned to the reading and the vacuum side of the manometer, which shifts much more slowly, was read as soon thereafter as possible. The mercury level on the high-pressure side was kept nearly constant, and all data were corrected for the variation in volume caused by variations in this level. These variations were small compared to the total dead-space volume. The influence of changes in room temperature and in the temperature of the liquid-nitrogen bath was followed over the duration of the experiment.

\section{EXPERIMENTAL RESULTS AND DISCUSSION}

\section{RATES OF ADSORPTION AND DESORPTION}

It is generally recognized that physical adsorption takes place at a relatively rapid rate. There are two well-known factors that could decrease the rate of such a process. The first is a slow dissipation of the heat of adsorption that increases the time in which a given increment of adsorption takes place, as the extent of physical adsorption at a given pressure decreases markedly with increase of temperature. In the experiments reported in this paper, this factor is minimized because of the fact that all measurements were made in a pressure range where 90 percent or more of surface is covered with 
adsorbed gas. Under conditions in which most of the adsorption is forming polymolecular layers, the heat of adsorption of nitrogen is but a few kilocalories per mole above the heat of liquefaction of nitrogen. The facilities for conducting these small heat evolutions to the surrounding bath are sufficient to prevent the heat developed from exceeding that which is conducted away.

The second factor retarding the rate of adsorption or that of desorption is the slow diffusion of gas molecules into the smaller interstices of the porous structure of the adsorbent. This possible effect of various pore-size distributions on the rate of physical adsorption of nitrogen was investigated by observing the rates on the three carbon adsorbents used in these experiments. It was known that the surface area per gram that was available to nitrogen molecules was greatest on coconut-shell charcoal-1 and that the adsorption isotherm for nitrogen on that material closely obeyed the Langmuir equation for monomolecular adsorption. New bone char-2, on the other hand, exhibited the least available surface, and the adsorption pursued an S-shaped isotherm typical of multimolecular adsorption. In comparison, the particular sample of activated carbon-6 was intermediate in these properties. Qualitatively, therefore, it might be expected that the ranges covered in the pore-size distributions of these adsorbents should increase in the following order: Coconut-shell charcoal, activated carbon, and bone char. The time required for these adsorbents to reach a steady state in adsorption, or desorption, should decrease in the same order.

The data presented in figure 1 relate to the dependency on time of the adsorption and of the desorption for these three samples. The curves present the change in the total amounts of gas adsorbed per gram of adsorbent with increase of time. The sharp bend of the curve is characteristic of a rapid approach to a steady state. A steady state is attained sooner, of course, for more rapid rates of adsorption or desorption than for less rapid rates. Consider first the progress of the adsorption on new bone char-2 at a relative pressure ${ }^{5}$ of 0.74 , for which data are presented in one of the upper curves of figure 1 . It appears that a "steady state" is attained in about 20 minutes, and that during the next hour and a half there is no measurable drift toward increased adsorption. In other instances a very slight drift toward increased adsorption was observed, never amounting to more than 0.02 milliliter of nitrogen $\left(\mathrm{STP}^{6}\right.$ per hour. Occasionally a slight drift in the opposite direction was observed. These drifts probably are consequences of changes in atmospheric pressure or other experimental conditions, as evidence now to be presented will indicate. It will be observed in the case of desorption from the bone char that a virtually steady state is attained in about 10 minutes. In anotber experiment in which the relative pressure was 0.77 , desorption was observed over a longer time. In this instance, however, no satisfactory conclusions could be drawn as a rising barometer, and the possible dissolubility of oxygen in the liquid nitrogen bath, led to an increase in the temperature of the bath corresponding to an increase in the saturation pressure, $p_{0}$, amounting to several millimeters of mercury. In such cases both the increase in temperature and the consequent lowering of the relative pressure lead to further desorption.

${ }^{5}$ By relative pressure is meant the ratio of $p$ to $p_{0}$, where $p=$ experimental pressure, $p_{0}=$ saturation pressure at the temperature of the isotherm.

${ }^{\circ}$ Standard temperature and pressure, namely $0^{\circ} \mathrm{C}$ and $760 \mathrm{~mm}$ of $\mathrm{Hg}$. 
In this particular experiment the amount of adsorbed gas decreased continually, but always to a smaller extent than would have been required to compensate for the effect of the increase in $p_{0}$.

In addition to fluctuations resulting from variations in the temperature of the bath, the rate experiments are limited in sensitivity by the limits of precision of the gas-measuring apparatus. The reproducibility of determinations of volume-for example, that of the empty adsorption bulb -is no better than 0.02 milliliter. This sets a lower limit to the drift that could be observed.

Turning to the adsorption on activated carbon-6, figure 1 shows

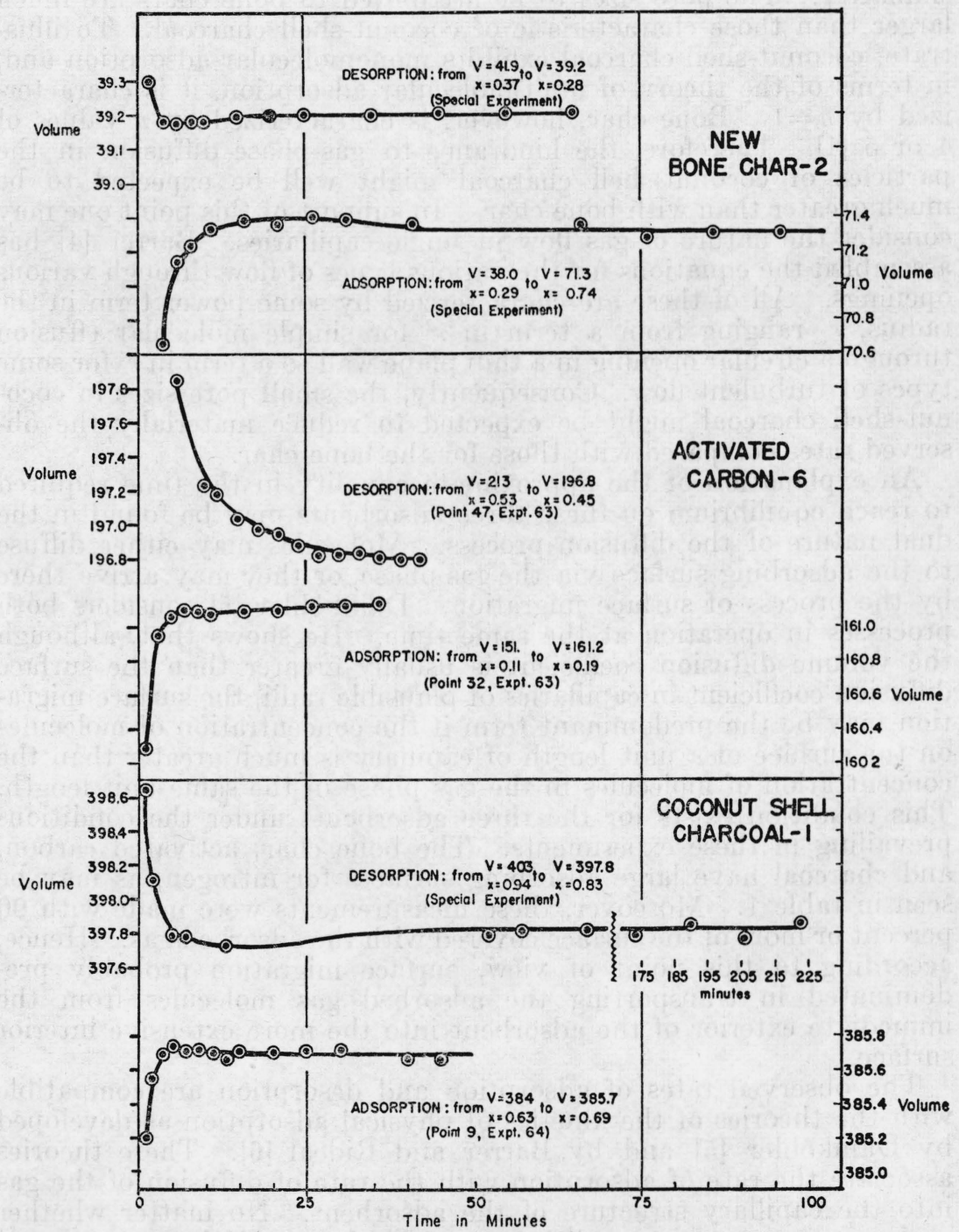

FigURe 1.-Adsorption and desorption of nitrogen on some carbon adsorbents at $7 \% .4^{\circ} \mathrm{K}$ as a function of time.

Volumes per gram of adsorbent, expressed as milliliters at standard temperature and pressure; time a minutes. 
that very little change occurs after the first 10 minutes. Desorption seems to be a little slower, requiring 25 minutes to reach fairly steady values. The sample of coconut-shell charcoal-1 shows a prompt attainment of an apparently steady state, as is evident from the lower part of figure 1. Both adsorption and desorption become quite steady within 10 minutes. In considering all of these data, it may be said that if there is, in general, a continued drift of the adsorption or desorption with time, then that drift is too slow to be determined precisely with the present apparatus.

The surprising feature about these time-dependent curves is their similarity. The pore sizes to be attributed to bone chars are much larger than those characteristic of coconut-shell charcoal. To illustrate, coconut-shell charcoal exhibits monomolecular adsorption and, in terms of the theory of multimolecular adsorption, it is characterized by $n=1$. Bone char, however, is characterized by $n$ values of 4 or 5 [1]. Therefore, the hindrance to gas-phase diffusion in the particles of coconut-shell charcoal might well be expected to be much greater than with bone char. In support of this point one may consider the nature of gas flow in single capillaries. Barrer [4] has assembled the equations for the various types of flow through various openings. All of these are characterized by some power term in the radius, $r$, ranging from a term in $r^{2}$ for simple molecular effusion through a circular opening in a thin plane wall to a term in $r^{4}$ for some types of turbulent flow. Consequently, the small pore sizes in coconut-shell charcoal might be expected to reduce materially the observed rates compared with those for the bone char.

An explanation of the approximate equality in the time required to reach equilibrium on these three adsorbents may be found in the dual nature of the diffusion process. Molecules may either diffuse to the adsorbing surface via the gas phase, or they may arrive there by the process of surface migration. Damköhler [5] considers both processes in operation at the same time. He shows that, although the volume diffusion coefficient is usually greater than the surface diffusion coefficient in capillaries of plausible radii, the surface migration may be the predominant term if the concentration of molecules on the surface of a unit length of capillary is much greater than the concentration of molecules in the gas phase in the same unit length. This condition exists for the three adsorbents under the conditions prevailing in these experiments. The bone char, activated carbon, and charcoal have large adsorbing surfaces for nitrogen, as may be seen in table 1. Moreover, these measurements were made with 90 percent or more of the surface covered with the adsorbed gas. Hence, according to this point of view, surface migration probably predominated in transporting the adsorbed gas molecules from the immediate exterior of the adsorbent into the more extensive interior surface.

The observed rates of adsorption and desorption are compatible with the theories of the kinetics of physical adsorption as developed by Damköhler [5] and by Barrer and Rideal [6]. These theories associate the rate of adsorption with the rate of diffusion of the gas into the capillary structure of the adsorbent. No matter whether surface migration or gas diffusion predominates in the transport of material to the adsorbing surface, the observed rates may be expected to vary according to some exponential law. As already mentioned, 
the two possible processes are distinguished by the numerical values of the diffusion constants and in their interpretation. Barrer and Rideal predict that initially

$$
\begin{gathered}
\left|V_{t}^{2}-V_{i}^{2}\right|=k t \text {, and finally, when }\left|V_{t}-V_{i}\right|>\left|V_{t}-V_{e}\right| \\
\qquad \log _{e} \mid \frac{\left|V_{e}-V_{t}\right|}{\left|V_{e}-V_{i}\right|}=k t,
\end{gathered}
$$

where $V_{t}$ represents the volume adsorbed at time $t, V_{i}$ the volume initially adsorbed, $V_{e}$ the volume adsorbed at equilibrium, $t$ is the time, and the $k$ 's are constants. The sorption is so rapid that in no experiments were data obtained that fit the first relationship. In order to plot the present data on carbon adsorbents according to the logarithmic expression, values for $V_{e}$ were chosen by extrapolation of the rate curves. When these values and the data are substituted in the logarithmic expression and the appropriate plot is made, the points are scattered about straight lines. Thus, these data are compatible with Barrer and Rideal's theory and with Damköhler's theory also, as his equation is formally equivalent to the second equation of Barrer and Rideal.

The role of surface migration in the mechanism of gas adsorption and desorption has a particular significance in regard to an explanation of hysteresis in physical adsorption. This will be discussed after the presentation of the hysteresis data for the adsorbents under investigation.

\section{HYSTERESIS DETERMINATIONS}

It may be noted from the data on the rates of adsorption and desorption that the measurements are substantially constant for both adsorption and desorption points after about 20 minutes. This is in agreement with the observations of Beebe and Dowden [7], who found that the adsorption of nitrogen, as well as five other gases, on chromic oxide at $-183^{\circ} \mathrm{C}$ was usually complete in 20 minutes. They further state: "The amount of gas adorbed in the interval between 2 and 20 minutes after admission was never more than 2 percent of the total increment adsorbed, and in most cases much less than that." In the experiments reported in this part of the present paper each point was observed for at least 20 minutes. It is estimated that the final measurements for each point accounted for about 99.5 percent of the increment that would have been absorbed if the previously defined steady state were attained.

The hysteresis loops that were observed in these experiments are presented in figures $2,3,4,5$, and 7 . Relative pressures are plotted as abscissas, and the quantities of nitrogen adsorbed, expressed in milliliters at STP, are plotted as ordinates.

The isotherms for bone chars are given in figures 2 and 3 . In figure 2 the adsorption isotherm was observed in experiment 61 up to a relative pressure of 0.99 by points 1 to 18 . Points 19 to 30 represent the desorption isotherm observed immediately after point 18 . The hysteresis loop closes at a relative pressure between 0.3 and 0.4 , this serving as a check on the numerous experimental manipulations. Throughout most of the hysteresis loop, the points on the desorption isotherm lie roughly 10 percent above the corresponding adsorption $665730-45-4$ 
values. It is to be noted that both the adsorption and desorption isotherms are of the type termed S-shaped and, between relative pressures 0.05 and 0.3 , the data conform quite accurately to the linear plot of the multimolecular theory, as we have previously shown [2]. Between 0.95 and 0.99 in relative pressure there is some evidence that adsorption and desorption isotherms again coincide. In this

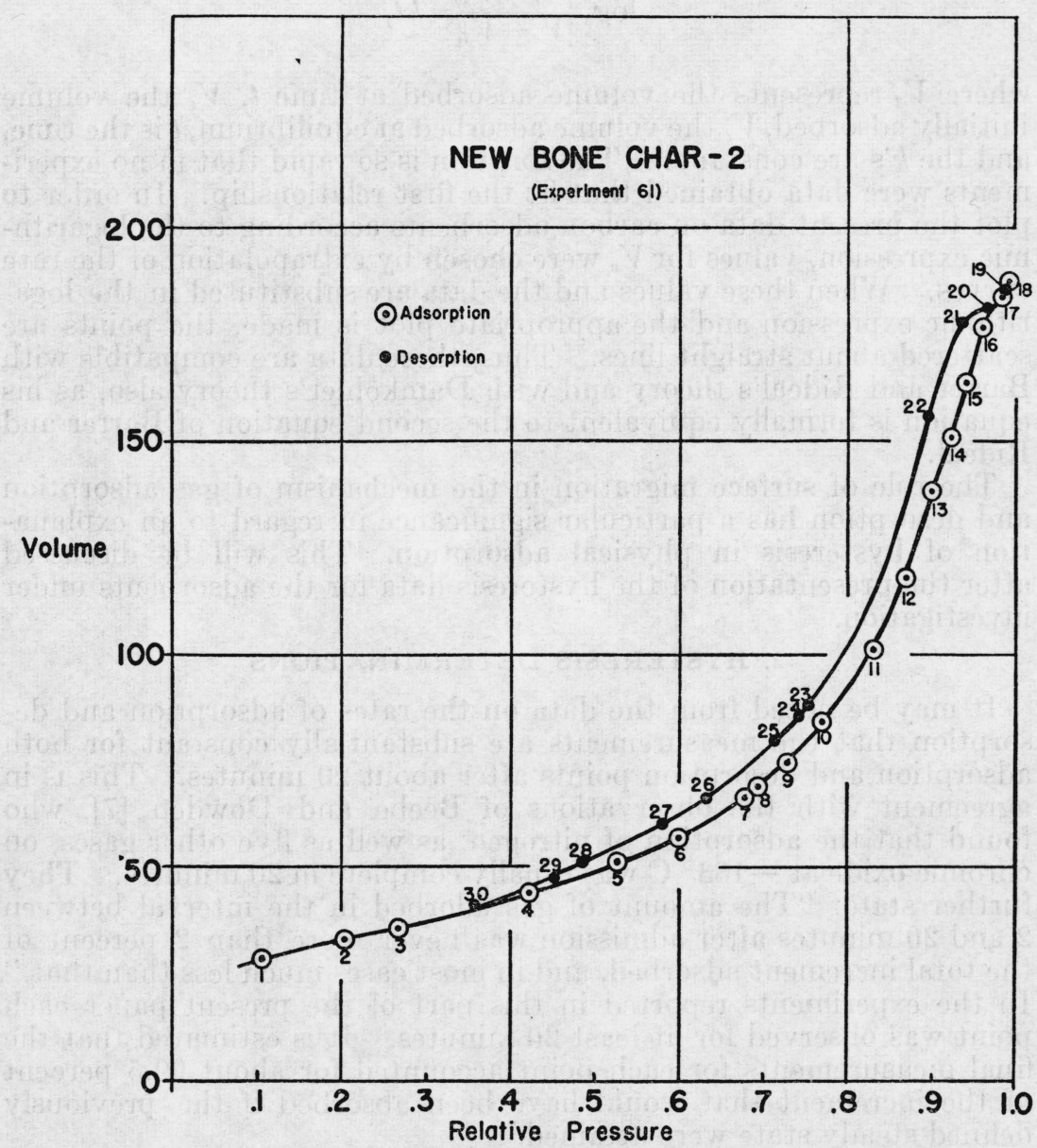

Figure 2.-Hysteresis in the physical adsorption of nitrogen on bone char-2 at $77.4^{\circ} \mathrm{K}$.

Ordinates represent volume adsorbed, per gram of adsorbent, expressed as milliliters at standard temperature and pressure. Abscissas, relative pressure, i. e., equilibrium pressures divided by the saturation pressure.

range there appears to be a leveling off of the isotherm such as occurs definitely in some other systems at a somewhat lower relative pressure.

Figure 3 presents additional data from four different experiments on bone chars, three on samples of the new bone char-2 employed in procuring the data given in figure 2 , and a fourth on a sample of spent bone char-27. The ordinate in figure 3 is the ratio $V / V_{m}$, and despite the wide difference in $V_{m}$ for these two bone chars (see table 1), 
the two adsorption isotherms superimpose on each other in this type of plot. Similar cases were reported in more detail in a previous publication [1]. In experiment 45a, points 1 to 9 represent the observations on adsorption, and points 10 to 13 those on desorption. This cycle was again repeated in experiment $45 \mathrm{~b}$, in which points 14 to 18 represent measurements on adsorption and points 19 to 24 on desorp-

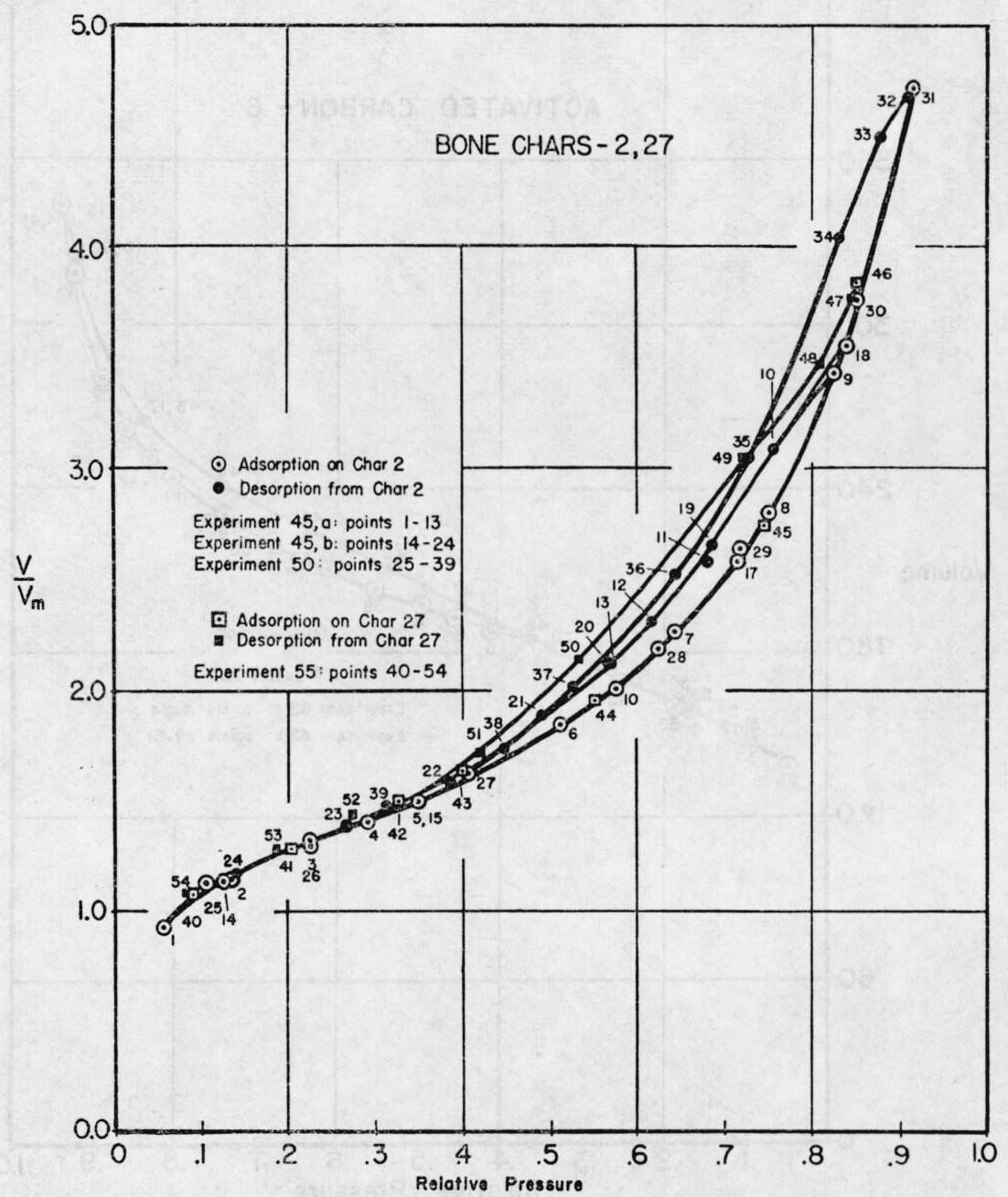

FIGURE 3.-Hysteresis in the physical adsorption of nitrogen on new bone char-2 and spent bone char-27, both at $77.4^{\circ} \mathrm{K}$.

Ordinates $v / v_{\mathrm{m}}$ represent the ratio of volume adsorbed at equilibrium to volume required to form a monolayer; $v_{m}$ was computed from the Brunauer, Emmett, and Teller equation. Abscissas represent relative pressures, $p / p_{0}$.

tion. The coincidence of the two adsorption and of the two desorption isotherms demonstrates the reproducibility of this particular hysteresis phenomenon. In experiment 50, which is taken to a higher relative pressure, the adsorption points 25 to 31 also fall on the isotherm of experiments $45 \mathrm{a}$ and $45 \mathrm{~b}$. However, the desorption isotherm defined 
by points 31 to 39 , lies above the previous desorption isotherm, as is usual in hysteresis phenomena. Although, as previously mentioned, the adsorption isotherm in experiment 55 for the spent bone char-27, points 40 to 46 in squares, coincides with the isotherm of char-2, the desorption isotherm covered by points 46 to 54 is different in that it

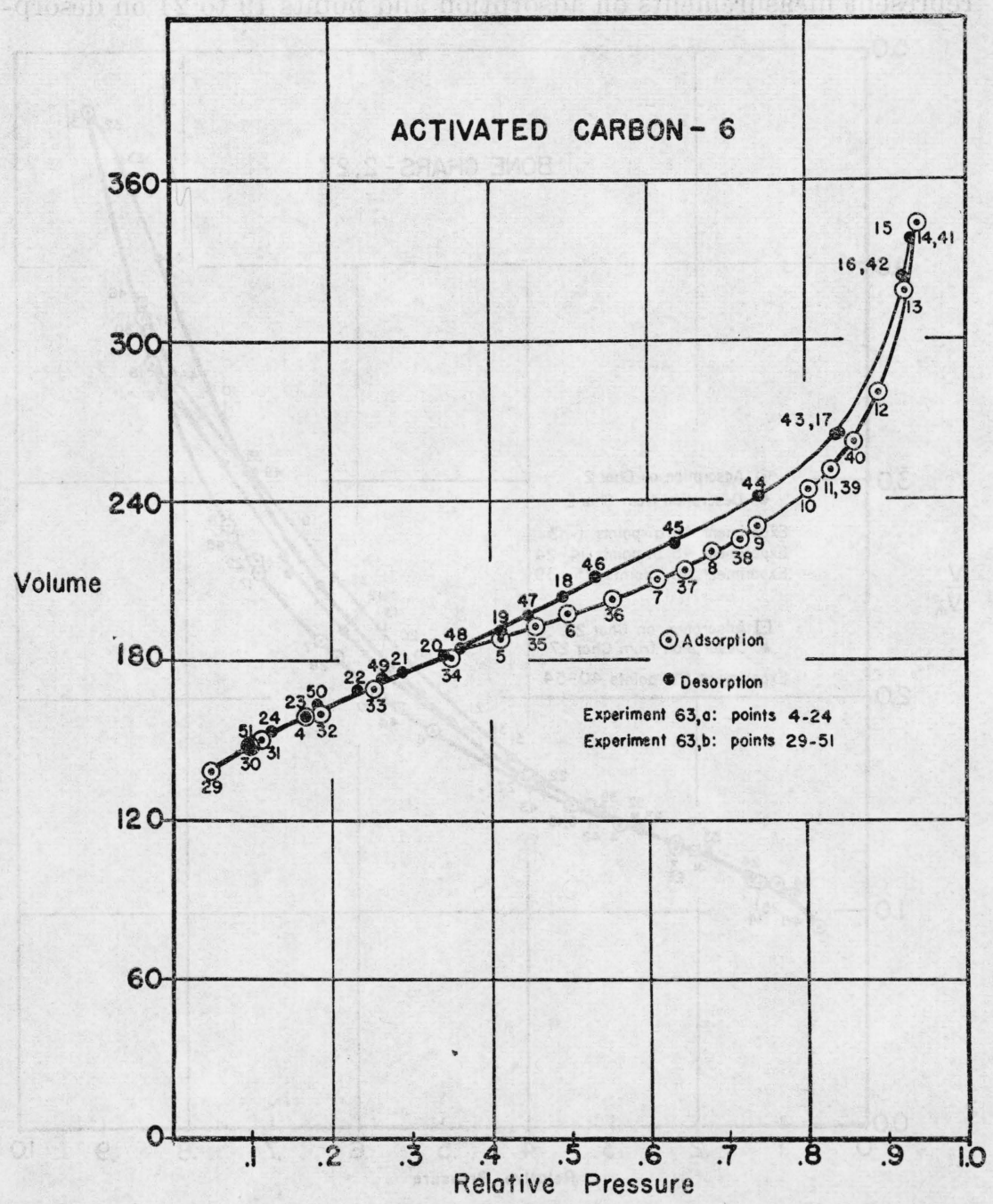

FIGURE 4.-Hysteresis in the physical adsorption of nitrogen on activated carbon- 6 at $77.4^{\circ} \mathrm{K}$.

Ordinates represent volumes, expressed as milliliters at stañdard temperature and pressure, adsorbed per gram of adsorbent. Abscissas represent relative pressures, $p / p_{0}$.

lies above that obtained for the new bone char-2, from which desorption began from an even higher relative pressure.

The isotherms in figure 4 obtained for the activated carbon- 6 are also of the S-shaped type, but are much flatter than those for char-2. The spread between the adsorption and desorption isotherms is 
smaller on a percentage basis than for the bone chars. Nevertheless, hysteresis is definitely present and, moreover, reproducible. In experiment 63a, points 1 to 14 determine the adsorption isotherm and points 14 to 24 the desorption isotherm. In the subsequent experiment $63 \mathrm{~b}$ with the same sample of activated carbon- 6 the points 29 to 41 fall on the first adsorption isotherm, and as desorption was started from the same relative pressure as in experiment $63 \mathrm{a}$, the points 41 to 51 fall on the desorption isotherm of that experiment.

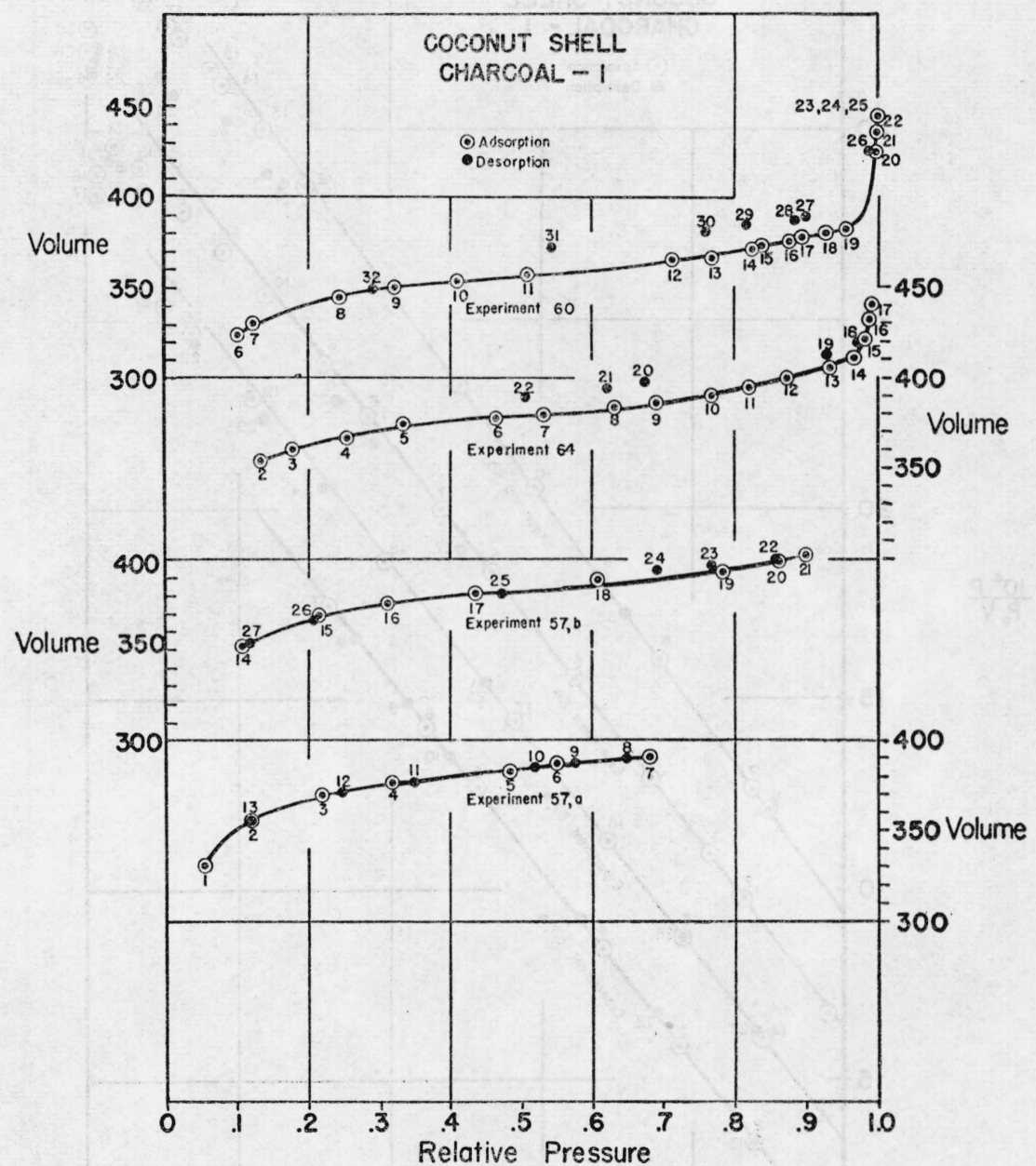

FiguRE 5.-Hysteresis in the physical adsorption of nitrogen on coconut-shell charcoal-1 at $7 \% .4^{\circ} \mathrm{K}$.

Ordinates represent volumes, expressed as milliliters, at STP, adsorbed per gram of adsorbent. Abscissas represent relative pressures, $p / p_{0}$.

The data for coconut-shell charcoal-1 are contained in figure 5 . Four experiments are presented, each approaching the saturation pressure of liquid nitrogen to different degrees. In the lowest curve, experiment $57 \mathrm{a}$, the adsorption was determined up to a relative pres- 
sure of 0.7. Desorption from this point followed the adsorption isotherm, and all data quite accurately obeyed the Langmuir equation for monomolecular adsorption. In the next-lowest curve of figure 5 , experiment $57 \mathrm{~b}$, the adsorption was observed up to a relative pressure of 0.9. Desorption from this pressure gave a small but definite indication of the presence of hysteresis, two points being

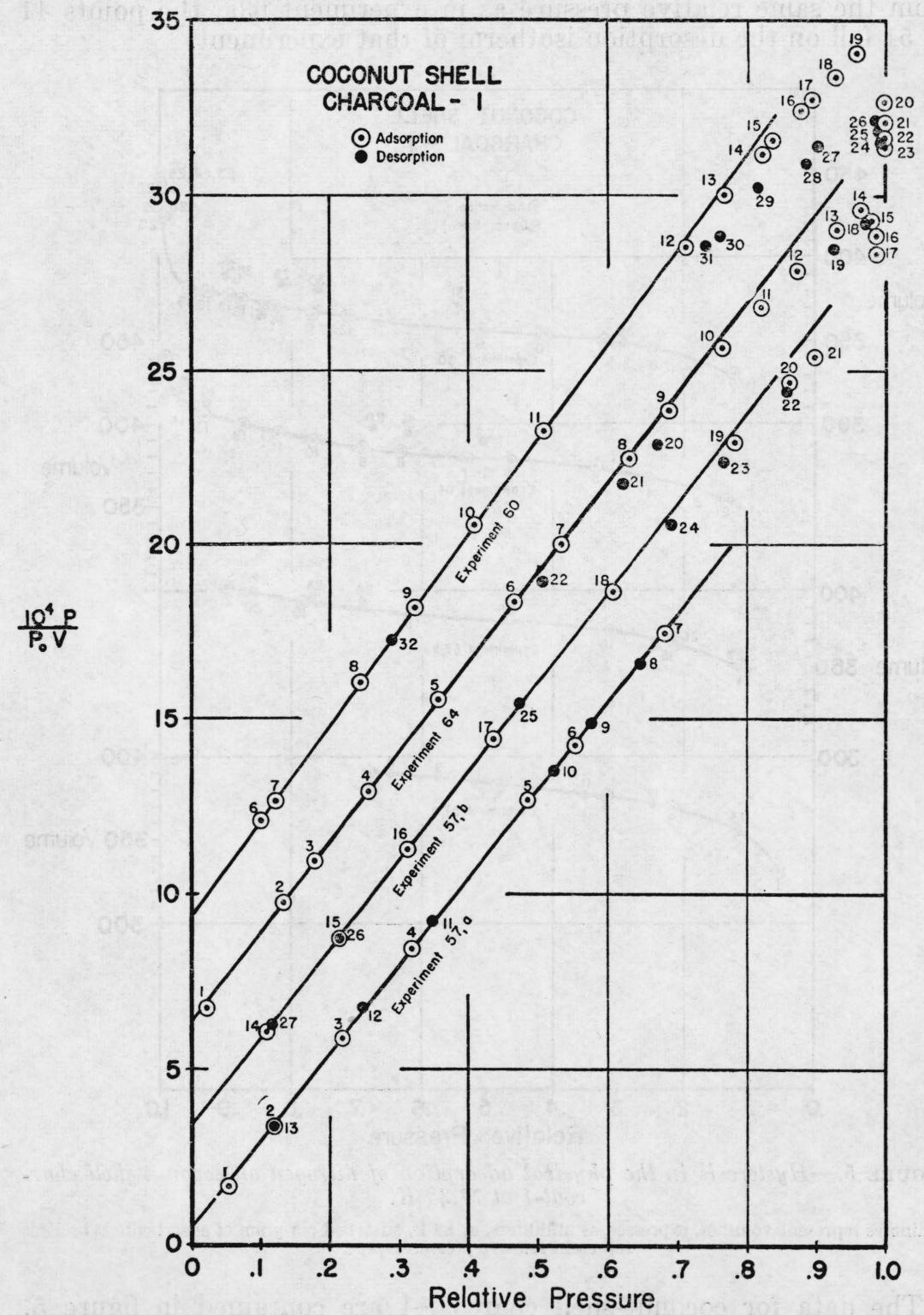

Figure 6.-A test of the Langmuir equation applied to data for adsorption of nitrogen on coconut-shell charcoal-1 at $77.4^{\circ} \mathrm{K}$.

The ordinates $\left(10^{4} p\right) / p_{0} v$ of the equation $p / v p_{0}=1 / C v_{\mathrm{m}}+p / p_{0} v_{\mathrm{m}}$ are displaced upward by 3 , 6, and 9 units respectively, for experiments $57 \mathrm{~b}, 64$, and 60 . Abscissas represent relative pressures, $p / p_{0}$. 
obtained above the adsorption isotherm. The spread in these data is greater than the relative experimental error in the measurements for a given experiment. However, when compared with either the bone char or the activated carbon-6, it is apparent that there is practically no hysteresis on coconut-shell charcoal if desorption begins at a relative pressure of 0.9 .

Several attempts were made to extend the adsorption on the coconut-shell charcoal to pressures in the neighborhood of saturation. The results obtained in experiments 60 and 64 are shown in the upper curves of figure 5. It may be observed that in the range above a relative pressure of 0.8 the points deviate from the linear curve required by the Langmuir equation. This is shown in figure 6, where it may be seen that the deviations are in the direction of increased adsorption, possibly because of multimolecular adsorption at the higher pressures. This excess over unimolecular adsorption is not the result of any known experimental error. In particular, no reasonable error in applying corrections to the ideal gas laws account for this increase in adsorption, when such corrections are applied to the nitrogen remaining in the dead space of the apparatus. Above a relative pressure of about 0.97 there is a sharp increase in adsorption which apparently causes the adsorptive isotherm (fig. 5) to approach the ordinate of saturation pressure tangentially. Upon desorption from these high relative pressures there is evidence of a hysteresis in which the loop closes at a relative pressure between about 0.3 and 0.4. Equilibration at high relative pressures is somewhat slower than at lower pressures, but as shown in the curve for the rate of desorption from coconut-shell charcoal in figure 1, a steady state is apparently obtained. From these data it would appear that hysteresis in the physical adsorption of nitrogen on coconut-shell charcoal is only realized upon desorption from pressures near saturation. The significance of this fact will be apparent when the various theories of hysteresis are reviewed.

Emmett and DeWitt [8] have observed that a leveling off in adsorption takes place beginning at a relative pressure of about 0.80 in the adsorption of nitrogen on porous glass samples at $79^{\circ} \mathrm{K}$. In the present research it was also observed to occur at a relative pressure of 0.7 in the adsorption of nitrogen on two samples of silica gel, although at lower relative pressures the contour of these isotherms differ from the shape of the porous glass and nitrogen isotherms. Data are presented in figure 7 for two different samples of commercial silica gels from the same manufacturer. As shown in table 1, the surface area of gel A was found to be 620 square meters per gram and that of gel B 765 square meters per gram. Although the surface of gel B is about 25 percent larger than gel $A$, it is interesting to note that in the plot of the ratio of $V / V_{m}$ against relative pressure, the isotherms for the two gels coincide. (Here $V$ is the volume of adsorbed gas, and $V_{m}$ is the volume of adsorbed gas necessary to cover the surface with a unimolecular layer.) The extent of hysteresis observed for these two samples of silica gel is small, but it is definitely greater than the experimental error.

The evidence for the reality of the hysteresis loops observed in these experiments may be summarized as follows: First, the adsorption branch, starting each time from a freshly outgassed adsorbent, is very satisfactorily reproducible for duplicate runs on a given sample, as for 
example experiments $45 \mathrm{a}$ and $45 \mathrm{~b}$ on a single sample of new bone char-2. In the second experiment the adsorption points 1 to 13 (fig. 3) were spaced more widely than in the first experiment, so that the total elapsed time to reach a relative pressure of 0.8 , for example, was only about half as long for the second experiment as for the first.

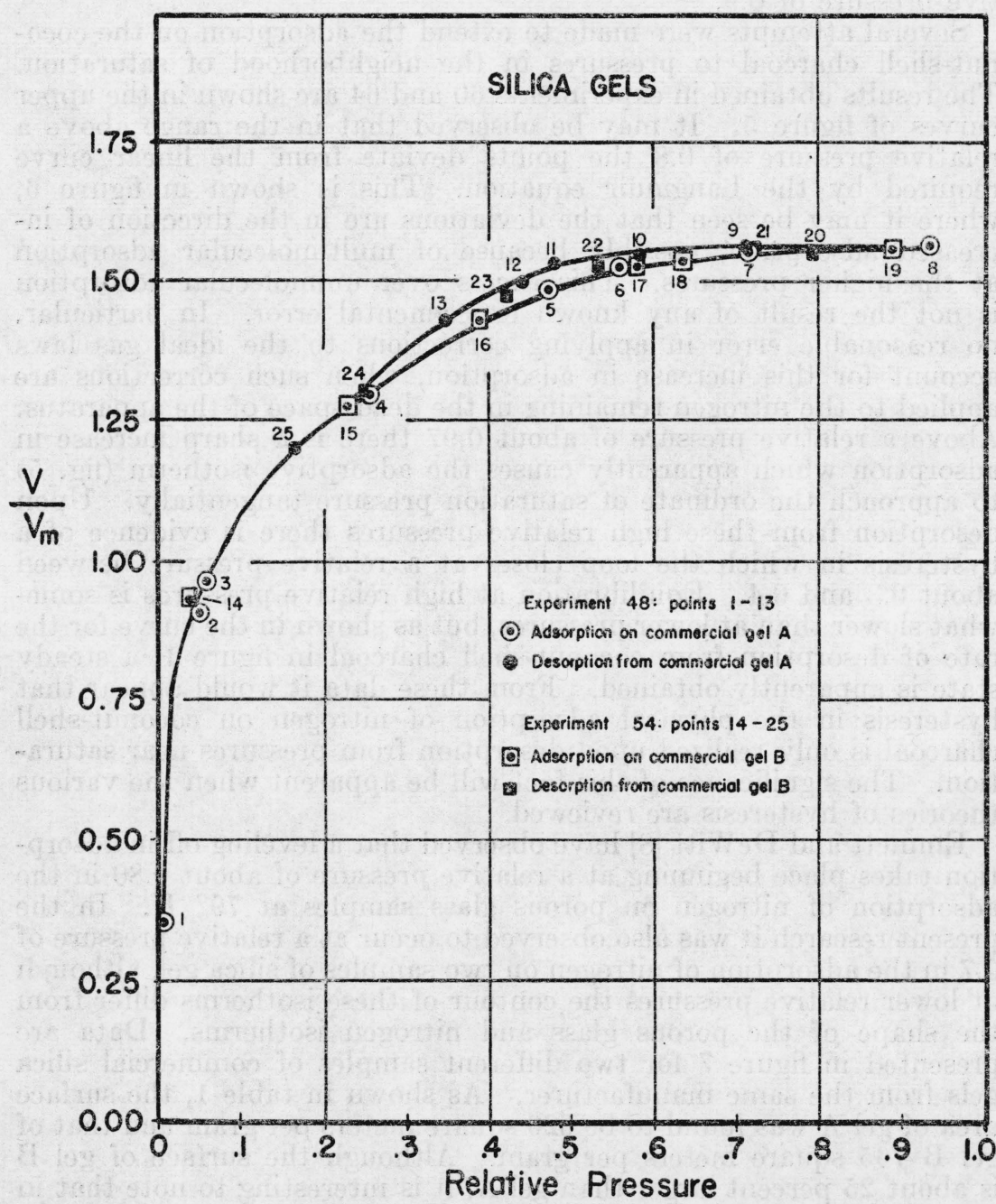

FiguRe 7.--Hysteresis in the physical adsorption of nitrogen on silica gel at $77.4^{\circ} \mathrm{K}$. Ordinates $v / v_{\mathrm{m}}$ represent the ratio of volume adsorbed at equilibrium to volume required to form a monolayer; $v_{m}$ was computed from the Brunauer, Emmett, and Teller equation. Abscissas represent relative pressures, $p / p_{0}$.

Nevertheless the two isotherms coincide very well. Second, the desorption isotherms were found to depend upon the maximum adsorptions from which they were begun. In experiment 50 on new bone char-2, shown in figure 3 , the points 25 to 39 were carried to a higher relative pressure and a greater total adsorption than in experiments 
45a and 45b. It may be seen that the desorption branch obtained by experiment 50 is distinctly above those of the other two isotherms. This behavior is characteristic of hysteresis in systems which, being more conveniently held at constant temperature, have been carefully investigated by many other workers. Third, the hysteresis loops close at the low-pressure end of the isotherms. If both adsorption and desorption always failed to reach their "steady states," there should invariably be a gap at this end of the loop. Concerning the possibility that equilibration may be complete in the region of coincidence of the adsorption and desorption isotherms but incomplete in the region of hysteresis, it may be said that the kinetics of adsorption and desorption appear to be altogether similar in the two regions. These three characteristics of the hysteresis loops constitute impressive evidence that the examples of hysteresis reported in this paper are real.

TABLE 1.-Constants derived for the physical adsorption of nitrogen on some commercial adsorbents

[Results of the surface calculations, where $v_{m}$ is the volume of nitrogen required to form a monomolecular layer on 1 gram of the adsorbent; the surface is in square meters per gram of adsorbent; $E_{1}-E_{L}$ is the difference between the average heat of adsorption in the first adsorbed layer and the heat of liquefaction of nitrogen.]

\begin{tabular}{|c|c|c|c|c|}
\hline Adsorbent & $\begin{array}{c}\text { Experiment } \\
\text { No. }\end{array}$ & $v_{m}$ & Surface & $E_{1}-E_{L}$ \\
\hline $\begin{array}{l}\text { New bone char-2 } \\
\text { Do } \\
\text { Do } \\
\text { Spent bone char-27 } \\
\text { Activated carbon-6. } \\
\text { Do.- } \\
\text { Coconut-shell charcoal-1 } \\
\text { Do } \\
\text { Do } \\
\text { Do } \\
\text { Silica gel A } \\
\text { Silica gel B }\end{array}$ & $\begin{array}{l}61 \\
45 \mathrm{a} \\
45 \mathrm{~b} \\
55 \\
63 \mathrm{a} \\
63 \mathrm{~b} \\
64 \\
57 \mathrm{a} \\
57 \mathrm{~b} \\
60 \\
48 \\
54\end{array}$ & $\begin{array}{c}m l / g \\
26.4 \\
26.9 \\
4.37 \\
142 \\
385 \\
396 \\
399 \\
366 \\
142 \\
175\end{array}$ & $\begin{array}{c}m^{2} / g \\
115 \\
117 \\
19.3 \\
623 \\
1,690 \\
1,740 \\
1,750 \\
1,610 \\
620 \\
765\end{array}$ & $\begin{array}{r}\mathrm{cal} / \text { mole } \\
1,000 \\
2,000 \\
400 \\
800 \\
700 \\
640 \\
620 \\
660 \\
790 \\
870\end{array}$ \\
\hline
\end{tabular}

The presence of hysteresis in the adsorption and desorption of nitrogen on charcoals and silica gels is significant because these phenomena do not seem to be obscured by such complications as extensive swelling of the adsorbent, pronounced asymmetry of the adsorbed molecules, and inadequate purification of the adsorbent. The swelling of charcoals during adsorption is so slight [9] that it is unlikely to cause extensive hysteresis of the kind described by Barkas [10]. The nitrogen molecule contains no dipole moment and no other instance of conspicuous asymmetry. The excellent reproducibility of adsorption isotherms on a given sample of char shows that the hysteresis effect cannot be caused by the gradual displacement of a film of adsorbed impurities according to the postulates of Zigmondy.

The surface areas of the adsorbents employed in this investigation, calculated by the method of Brunauer, Emmett, and Teller [2], are summarized in table 1. Hexagonal close-packing in liquid nitrogen was assumed to occur on the adsorbing surface, and an effective area of 4.37 square angstrom units [1] was covered by each milliliter of adsorbed nitrogen at $77^{\circ} \mathrm{K}$. 


\section{THEORIES OF HYSTERESIS IN PHYSICAL ADSORPTION}

\section{CAPILLARY CONDENSATION}

A comprehensive review of the various theories of hysteresis in physical adsorption has been given recently by Brunauer [12], and recent discussions on the subject have been presented by Rao [11], Emmett and DeWitt [8], and Cohan [14]. An examination of these theories reveals that those that are applicable to well outgassed adsorbents involve the concept of capillary condensation. This concept has not been very successful in interpreting quantitatively the general phenomena of adsorption. However, it seems to offer a partial explanation of hysteresis.

It is recognized on thermodynamic grounds that when a liquid is constrained to present a curved surface, its vapor pressure differs from the vapor pressure of a plane surface of the same liquid. In particular, if the curvature be concave, the vapor pressure is reduced and condensation can occur at pressures less than the normal saturation pressure of the liquid. In the case of a spherical meniscus this behavior is quantitatively given by the classical Kelvin equation, which relates the radius of curvature, $r$, to the ratio of the vapor pressure of the confined liquid, $p$, to that of the liquid in bulk, $p_{0}$, as follows:

$$
\ln p / p_{0}=\frac{-2 \gamma v}{r R T} .
$$

Here $\boldsymbol{\gamma}$ is the surface tension; $v$ is the molar volume of the liquid; $R$ is the gas constant, and $T$ is the absolute temperature.

In applying this relationship to adsorption phenomena, the solid adsorbent is conceived as possessing numerous pores of various shapes and sizes. For mathematical simplicity it is usually assumed that the actual system of pores is equivalent to a hypothetical system of pores having regular geometric forms, such as cylinders. Such a cylindrical capillary will be either completely filled or entirely empty at any particular pressure, as is required by the Kelvin equation. In order to account for the smooth, continuous adsorption isotherms which are found experimentally, it is, therefore, necessary to postulate a continuous distribution of capillaries of gradually increasing radii. Unfortunately, these capillary radii are not subject to independent determination, but are deduced from the adsorption isotherm which they are intended to explain.

It should be possible, nevertheless, to test the self-consistency of the pore-radius distribution for a given adsorbent by evaluating the distribution from an isotherm for a particular vapor, and then by comparing this distribution with others obtained from isotherms of other vapors. Also, the total volumes, as liquids, adsorbed at saturation pressure may be compared for several vapors. In regard to the experimental test of these two conditions, it may be said that they are qualitatively fulfilled. As to the first possibility, Brunauer [12] has examined the available experimental results and has shown the lack of quantitative agreement. Assuming the validity of the unmodified Kelvin equation and using normal values for the surface tension and the molecular volumes of the adsorbed vapors, Brunauer demonstrates that the pore-radius distribution curve for a given adsorbent is not independent of the vapor employed. Apparently the adsorbent can- 
not be considered as entirely inert, presenting merely an array of capillaries of various sizes to the adsorbed gas. With regard to the second experimental test, there are a number of cases in which the volume of adsorbed liquid, determined at saturation pressure, has been observed to be constant for various vapors with the same adsorbent. However, there are also a large number of cases in which the adsorption isotherm approaches saturation at a very steep slope. Consequently, it is difficult to estimate the quantity of vapor adsorbed at saturation pressure.

The most useful application of the concept of capillary condensation has been in explaining hysteresis. Theories attempting to explain hysteresis loops of the type presented in figures $2,3,4,5$, and 7 have been three in number. The oldest is known as the Zsigmondy theory of partial wetting [12]. This is based on the observation that the angles of contact, $\theta$, between a solid and the liquids that wet it depends upon whether the liquid is advancing over or receding from the solid surface. The difference between the "advancing" and the "receding" angles of contact is often called the hysteresis of the contact angle. When applied to the capillary condensation theory of adsorption, it is assumed that partial wetting occurs in adsorption. This imperfect wetting is attributed to impurities, mostly permanent gases, adsorbed on the walls. The equilibrium pressures are given by the equation

$$
\ln p / p_{0}=\frac{-2 \gamma v \cos \theta}{r R T} .
$$

At saturation pressure a complete wetting of all surfaces takes place. Subsequently the desorption equilibrium takes place from a completely wetted surface, in which $\theta=0$ degrees and, therefore, corresponds to equation 1 . As a consequence, the values of $p / p_{0}$ calculated for a given radius would be greater in adsorption than in desorption. The serious objection, however, to this explanation of hysteresis is the reproducibility of data in repeated cycles of adsorption and desorption that is obtained with highly evacuated samples. Whereas in some cases it is possible to eliminate hysteresis by drastic evacuation technic, in other cases it is not possible to do so. This rules out the Zsigmondy theory of partial wetting as a general explanation of reproducible hysteresis.

The Kraemer and McBain "bottleneck" theory of capillary condensation assumes the presence of constricted regions in capillaries with one end open. According to this theory, hysteresis results from the following conditions: The narrow neck fills at low relative pressures, but condensation in the body of the capillary takes place only at a higher relative pressure determined by the larger radius; in desorption the pores empty only when the pressure is reduced so that the liquid in the constricted region becomes unstable. This condition of instability is determined by the smaller radius of the neck. Upon being released, the liquid condensed in the larger part of the pores is immediately desorbed. In this way the amount of gas desorbed for a given decrease in pressure is less than the corresponding amount adsorbed until a lower pressure is reached corresponding to the radius of the constriction. Unfortunately, this ingenious explanation of hysteresis is not amenable to quantitative treatment as there is no way of obtaining information concerning the volumes of the various pores and the radii of their wide and narrow parts. 
The third explanation of hysteresis, also in terms of capillary condensation, assumes the presence in the adsorbent of cylindrical capillaries without constrictions and with both ends open. If a capillary is open at both ends, L. Cohan [14] has shown that a meniscus cannot form during the adsorption process. Condensation is assumed to occur, however, at a suitable relative pressure on a unimolecular layer already adsorbed to the inner cylindrical surface. This condensation forms an annular ring, or shell, of liquid on the wall. The entire capillary will then fill, as any inner annular ring has a lower vapor pressure than the outermost one. It was shown by Cohan [14] that the relative pressure is given by equation 3 , where $r_{1}$ is the radius of the annular ring:

$$
\ln \left[p / p_{0}\right]=\frac{-\gamma v}{r_{1} R T}
$$

Desorption, on the other hand, occurs from the meniscus formed when the capillary is full, and takes place according to equation 1 with $r=r_{1}$, assuming complete wetting of the surface. There are two aspects of this theory which are subject to a quantitative test. The theory predicts that the radius at which hysteresis begins, $r_{h}$, should be not less than $2 D$, where $D$ is the diameter of the adsorbed molecule. Assuming hexagonal close packing in three dimensions for liquid nitrogen at $77.8^{\circ} \mathrm{K}, D=4.33$ angstroms. This value corresponds to an average area of 16.22 square angstroms per nitrogen molecule. For this value of $D, r_{h}$ cannot be less than 8.66 angstroms, which corresponds to a relative pressure of about 0.33 , when $\gamma=8.8$ and $v=34.7$. The data obtained for carbon adsorbents and silica gels in this investigation are in agreement with this conclusion. If the capillary condensation is assumed to occur after a unimolecular layer is formed, then $D$ must be measured from the surface of this layer and not from the wall. The second prediction is that for a given volume of gas adsorbed in the region of hysteresis, the relative pressure on the desorption curve should equal the square of the relative pressure on the adsorption curve. This may be seen by combining equations 1 and 2. The data obtained in this investigation are not in agreement with this prediction in any pressure region of the hysteresis loops.

This open-pore theory has the advantage of being subject to certain quantitative tests, but all of these explanations involving capillary condensation suffer the following defects:

(a) The capillary radii are not subject to independent determination, but are deduced from the sorption isotherm which they are supposed to explain.

(b) There is no adequate means of determining: what fraction of the capillary radii are constricted and thus contribute to hysteresis in an indefinite manner; what fraction are open and nontapering and thus contribute to hysteresis in a supposedly definite manner; and what fraction are tapered, or V-shaped, and do not contribute to hysteresis at all.

(c) The many and varied assumptions that have been proposed to modify the capillary condensation theory (specifically the proposed changes in the surface tension, the density of the condensed liquid, the angle of contact between liquid and wall, and the size, shapes, and distribution of pore radii), do not constitute a completely logical 
approach to the general phenomena of adsorption in terms of fundamental molecular theory.

(d) The necessity of accounting for at least the first layer of adsorbed gas remains as an independent problem. One does not know whether the capillary condensation is to be considered as being superimposed upon Langmuir adsorption or upon some more complex type of adsorption, which results from the interaction between the unbalanced forces on the surface atoms and the atoms of the adsorbate.

\section{MULTIMOLECULAR ADSORPTION}

Hysteresis phenomena in adsorption may apparently be divided into two main classes from an experimental point of view. The high-pressure end of the hysteresis loop may close either at a relative pressure definitely below saturation (e. g., $x=0.8$ for the silica gels), or the desorption isotherm may differ from the adsorption isotherms up to pressures very close to saturation without any indication of leveling off. The leveling off of adsorption isotherms is generally interpreted as indicating the stage where the pore structure has been completely filled with adsorbate. Hence where this does not occur, it is difficult to estimate an average pore radius for the adsorbent. Present-day concepts endeavor to classify the various types of hysteresis loops shown by adsorbents in relation to variations in such an average pore radius. For example, Coelingh [13] suggests the following classifications: (1) The very narrow pores of chabasite and some charcoals are too small to exhibit capillary condensation; thus the adsorption and desorption isotherm coincide and no hysteresis is evident, (2) charcoals having wide pores and silica gels having narrow pores, both with pore radii in the neighborhood of 10 angstroms, show hysteresis for small molecules like $\mathrm{H}_{2} \mathrm{O}$ and $\mathrm{N}_{2}$, but no hysteresis for larger molecules, (3) still larger pores show hysteresis for all vapors, and (4) hysteresis in very large pores may extend so close to the saturation pressures that the hysteresis loop cannot be accurately determined. This classification may be overly simplified.

It is now suggested that the concept of hysteresis can be incorporated into the multimolecular theory of adsorption as presented by Brunauer, Deming, Deming, and Teller [15]. These authors have developed a general theory in which the five types of adsorption isotherms may be deducted from a single equation. They attribute the leveling off in the upper portions of certain adsorption isotherms to the increased value for the heat of adsorption of the last layer of molecules, which fill a capillary-like structure. This last adsorbed layer is attracted from either side and, correspondingly, its heat of adsorption $\left(E_{L}+Q\right)$ can be expected to be greater than that of any layer except the very first adsorbed layer. The equation derived by these authors is

where $A$ equals

$$
v=v_{m}\left[\frac{x}{1-x}\right]+A
$$

$\underline{\left.2(c-1) x+2(c-1)^{2} x^{2}+\overline{(n} c^{2}+\bar{n} h-2 \bar{n} c-n^{2} c^{2}\right) x^{n}+\left(2 c+\bar{n}^{2} c^{2}+2 \vec{n} c-c^{2}[(2+\bar{n})-2 h(1+\bar{n})] x^{\bar{n}+1}+(\bar{n} h+2 h) x^{\bar{n}+2}\right.}$. $2\left[1+2(c-1) x+(c-1)^{2} x^{2}+\left(c^{2}+h-2 c-\bar{n} c^{2}\right) \bar{x}^{\bar{n}}+\left(\bar{n} c^{2}+2 c-2 c^{2}-2 h\right) x^{\bar{n}+1}+h x^{\bar{n}+2}\right]$

In equation 4 and in the expression for $A, v$ is the volume of gas adsorbed; $v_{m}$ is the volume of gas which is required to cover the 


\section{Journal of Reseurch of the National Bureau of Standards}

surface with a monomolecular layer; $x$ is the relative pressure; $\bar{n}$ is the maximum number of layers that can fit into the capillary; $c$ is a constant related to the increase of the heat of adsorption over the heat of liquefaction $\left(E_{L}\right)$, namely $E_{1}-E_{L}=2.303 R T \log c$, in which $E_{1}$ is the heat of adsorption in the first layer, $R$ is the gas constant, and $T$ is the temperature; $h=\left(\bar{n} c^{2}-c^{2}+2 c\right) g$, where $g$ is related to the additional energy, $Q$, by the expression, $g=e^{Q / R T}$.

Good agreement was found by Brunauer, Deming, Deming, and Teller in applying the above rather formidable equation to the data of Lambert and Clark [16] for the adsorption of benzene on a ferric oxide gel. The constants $v_{m}=0.082$ gram of benzene per gram of gel, $c=27$ (corresponding to $E_{1}-E_{L}=2,110$ calories), $h=47,400$ (corresponding to $Q=1,690$ calories), and ( $\bar{n}=6$ were used to calculate the lower curve in figure 8 . This agrees very favorably with the experimental points in the circles. The agreement is more remarkable when the simplifying assumptions used in developing the theory are considered. In the mathematical derivation of equation 4 it was assumed that the adsorption takes place between plane parallel walls and that all pores throughout the adsorbent are of uniform width.

It is now pointed out that an isotherm agreeing with the desorption data can be calculated to fit the experimental data of Lambert and Clark by changing one constant in the previous calculation. The identical values for $V_{m}, c$, and $\bar{n}$ are used as in adsorption, but $h$ is increased to 164,100 . This change in $h$ corresponds to increasing $Q$, by 760 calories, to 2,450 calories. This increase in $Q$ signifies that in the region of hysteresis the heat of desorption is greater than the heat of adsorption. The increment of 760 calories was determined from the data of Lambert and Clark and represents the difference between the average differential heats of desorption and of adsorption calculated by means of the application of the Clapeyron-Clausius equation to the $40^{\circ}$ and $60^{\circ} \mathrm{C}$ isosteres, representing 0.15 to 0.19 gram of benzene adsorbed per gram of gel. In this range the average values of the calculated heats were 8,660 calories for adsorption and 9,420 calories for desorption, the difference being 760 calories. The calculated desorption isotherm, the larger value of $Q$ being used, is shown as the upper curve in figure 8. Agreement with the experimental desorption points is not all that could be desired, but it is certainly all that could be expected. It is remarkable that a change in one particular constant of equation 4 is all that is required to change the isotherm to correspond to the course of the desorption process. It is to be noted that as the hysteresis loop closes, the calculated differential heats of adsorption and of desorption become equal. This may account in part for the deviation between theory and experiment in the lower and upper parts of the desorption branch.

A plausible significance may be attached to the above procedure in that it attributes hysteresis to some fundamental change in the adsorbed layer that takes place at a relative pressure near saturation. A stability of the adsorbed layer to subsequent evaporation results, as evidenced from the increase in the numerical value of $Q$. A multimolecular layer of adsorbate may be viewed as a physical state whose similarity to the liquid bulk phase must be complete at saturation pressures. Until that similarity is reached there are many inter- 
mediate configurations possible in the complex structure of the multimolecular layer. The situation may be analogous to the clusters postulated by J. E. Mayer [17] in his explanation of the phenomena of the critical state by means of a statistical theory of condensing systems. It suggests that molecular clusters of various sizes may

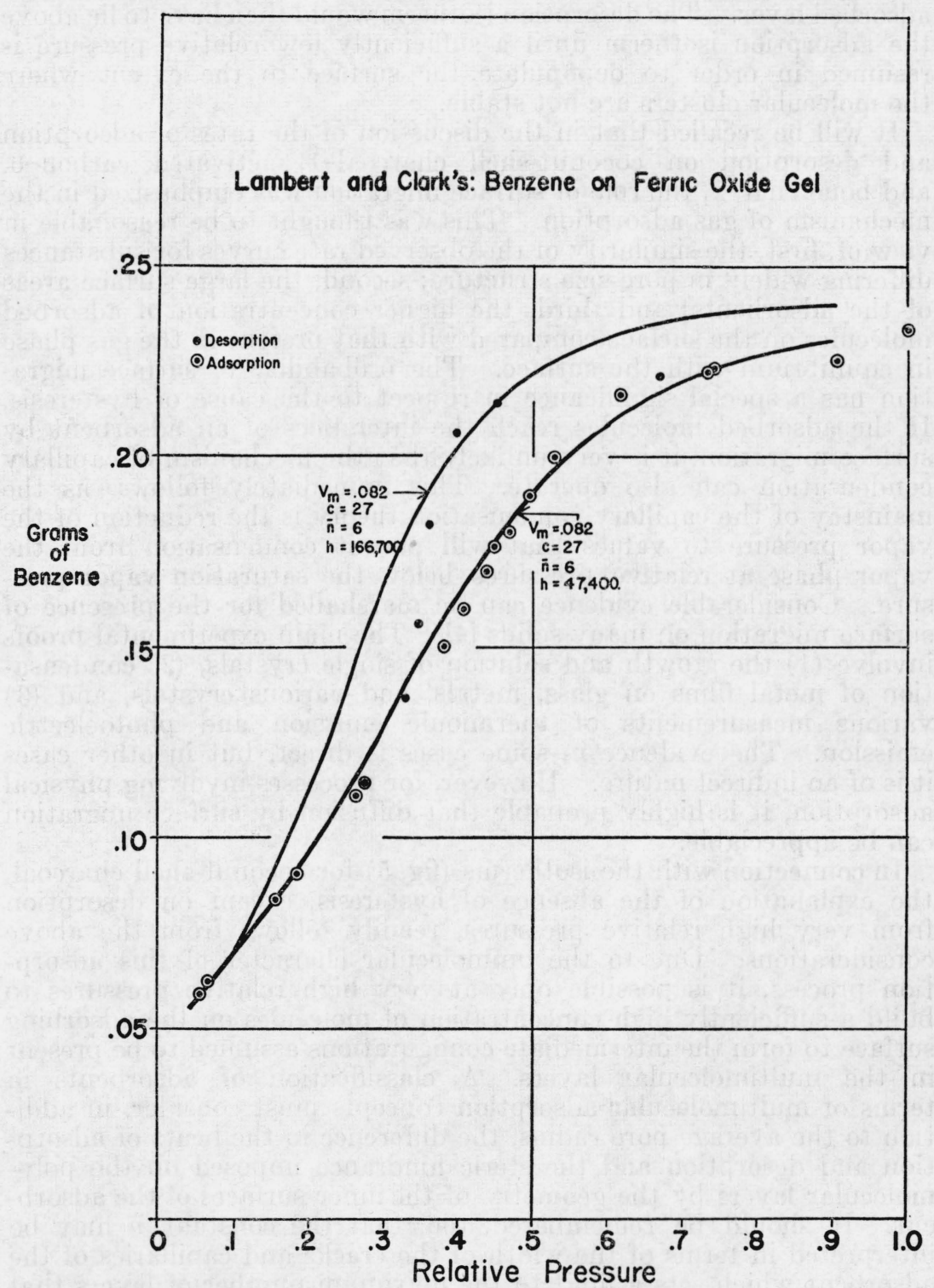

Figure 8.-Calculated isotherms according to the theory of Brunauer, Deming, Deming, and Teller for the data of Lambert and Clark on the adsorption of benzene on a ferric oxide gel.

Ordinates represent grams of benzene adsorbed per gram of gel and abscissas represent relative pressures, $p / p_{0}$. 
form gradually at many points on the surface, depending upon the interaction between the adsorbent and the adsorbed layers. These large aggregates may be independent of each other (but in a statistical equilibrium with the vapor) until a certain relative pressure is attained, at which point they are modified by joining together in some fashion. Subsequently, desorption would have to occur from this modified adsorbed layer. The desorption isotherm would then have to lie above the adsorption isotherm until a sufficiently low relative pressure is resumed in order to depopulate the surface to the extent where the molecular clusters are not stable.

It will be recalled that in the discussion of the rates of adsorption and desorption on coconut-shell charcoal-1, activated carbon-6, and bone char-2, the role of surface migration was emphasized in the mechanism of gas adsorption. This was thought to be reasonable in view of, first, the similarity of the observed rate curves for substances differing widely in pore-size structure; second, the large surface areas of the adsorbents; and third, the higher concentration of adsorbed molecules on the surface compared with that present in the gas phase in equilibrium with the surface. The probability of surface migration has a special significance in respect to the cause of hysteresis. If the adsorbed molecules reach the interstices of an adsorbent by surface migration, it is very unlikely that the mechanism of capillary condensation can also operate. This immediately follows, as the mainstay of the capillary condensation theory is the reduction of the vapor pressure to values that will permit condensation from the vapor phase at relative pressures below the saturation vapor pressure. Considerable evidence can be marshalled for the presence of surface migration on many solids [4]. The main experimental proofs involve (1) the growth and solution of single crystals, (2) condensation of metal films on glass, metals, and various crystals, and (3) various measurements of thermionic emission and photoelectric emission. The evidence in some cases is direct, but in other cases it is of an indirect nature. However, for processes involving physical adsorption, it is highly probable that diffusion by surface migration can be appreciable.

In connection with the isotherms (fig. 5) for coconut-shell charcoal, the explanation of the absence of hysteresis, except on desorption from very high relative pressures, readily follows from the above considerations. Due to the unimolecular character of this adsorption process, it is possible only at very high relative pressures to build a sufficiently high concentration of molecules on the adsorbing surface to form the intermediate configurations assumed to be present in the multimolecular layers. A classification of adsorbents in terms of multimolecular adsorption concepts must consider, in addition to the average pore radius, the difference in the heats of adsorption and desorption and the steric hindrance imposed on the polymolecular layers by the geometry of the inner surfaces of the adsorbent. It should be remembered, too, that the constant $\bar{n}$ may be interpreted in terms of the width of the cracks and capillaries of the adsorbent which sets a limit to the maximum number of layers that can be adsorbed even at saturation pressure. At this pressure the limiting value of $V / V_{m}$ should be equal to $\bar{n} / 2$, as layers are building outward from both walls. It may be seen from figure 8 that the limiting value of $V / V_{m}=3$ for the data of Lambert and Clark is 
consistent with the value of $\bar{n}=6$. As Brunauer, Deming, Deming, and Teller point out, this is true only if the value of $g$ is high and that of $\bar{n}$ is low. Elsewhere the experimental value for $V / V_{m}$ is usually less than $\bar{n} / 2$. This is understandable as the multimolecular theory of adsorption has not treated the interaction of each molecule with its neighbor.

Hysteresis in the physical adsorption of gases remains as one of the outstanding problems in the field of adsorption. The phenomenon is recognized to be very complex and to be immediately confronted by the relatively limited progress that has been made in the fundamental study of condensed systems. The investigations based on capillary condensation theories, as pointed out in the first section of this discussion, are of limited application. The multimolecular theory of adsorption, however, may be considered as an alternative approach to the problem with some advantages for the moment in guiding researches in this field.

\section{SUMMARY}

The physical adsorption and desorption of nitrogen were observed for samples of coconut-shell charcoal, activated carbon, and bone char. It was shown that good approximations to final steady states were obtained in the experiments. No appreciable differences were observed in the time dependency of adsorption or desorption on these adsorbents. From the isotherms for adsorption and desorption it was shown that the magnitude of the hysteresis effect decreased in the order: bone char, activated carbon, silica gel, coconut-shell charcoal. On the lastnamed substance, hysteresis was shown to occur only if the desorption process was begun very close to saturation pressure-a region in which the Langmuir equation of unimolecular adsorption was not obeyed. The explanations of hysteresis, on the basis of capillary condensation, were reviewed, and an alternative interpretation was suggested in terms of the theory of multimolecular adsorption.

\section{REFERENCES}

[1] V. R. Deitz and L. F. Gleysteen, J. Research NBS 29, 191-225 (1942) RP1496.

[2] S. Brunauer, P. H. Emmett, and E. Teller, J. Am. Chem. Soc. 60, 309-19 (1938).

[3] V. R. Deitz and L. F. Gleysteen, J. Research NBE 28, 795-805 (1942) RP1479.

[4] R. M. Barrer, Diffusion in and through solids, 464 pages (Cambridge University Press, England, 1941).

[5] G. Damköhler, Z. physik. Chem. [A] 1\%4, 222-38 (1935).

[6] R. M. Barrer and E. K. Rideal, Proc. Roy. Soc. [A] 149, 231-53 (1935).

[7] R. A. Beebe and D. A. Dowden, J. Am. Chem. Soc. 60, 2912-22 (1938).

[8] P. H. Emmett and T. W. DeWitt, J. Am. Chem. Soc. 65, 1253-62 (1943).

[9] D. H. Bangham and R. F. Razouk, Proc. Roy. Soc. [A] 166, 57-86 (1938).

[10] W. W. Barkas, Trans. Faraday Soc. 38, 447-62 (1942).

[11] K. S. Rao, J. Phys. Chem. 45, 500-31 (1941).

[12] S. Brunauer, Physical Adsorption, chapter XI, 511 pages (Princeton University Press, Princeton, N. J., 1943).

[13] M. B. Coelingh, Kolloid Z. 87, 251-72 (1939).

[14] L. Cohan, J. Am. Chem. Soc. 66, 98-105 (1944).

[15] S. Brunauer, L. S. Deming, W. E. Deming, and E. Teller, J. Am. Chem. Soc. 62, 1723-32 (1940).

[16] B. Lambert and A. M. Clark, Proc. Roy. Soc. [A] 122, 497-512 (1929).

[17] J. E. Mayer and M. G. Mayer, Statistical mechanics, page 312, 502 pages (John Wiley \& Sons, Inc., New York, N. Y., 1940).

$665730-45-5$ 